\title{
Walter Benjamin, tradutor de Baudelaire
}

\section{Susana Kampff Lages ${ }^{1}$}

\begin{abstract}
"Les parfums, les couleurs e les sons se répondent..."
Charles Baudelaire

“... e, portanto, também as línguas, pois que são sons e são cores, e são perfumes."
\end{abstract}

Guilherme de Almeida

“... do texto original, o tradutor só possui a memória."

JAVIER MaríAS

Toda a obra de Walter Benjamin pode ser lida, mais do que o produto de um trabalho do pensamento (Denken), como produto trabalho de rememoração (Andenken). Os atos de pensar e rememorar atravessam, pari passu, os escritos benjaminianos e, em particular, determinam não tanto a passagem, em seu percurso teórico, do plano de uma idéia da tradução em geral para o plano da tradução como leitura, como apontou Sigrid Weigel, ${ }^{*}$ como a passagem - através de seus escritos - de constelações conceituais compostas por diferentes aspectos da memória (Gedächtnis), da lembrança (Erinnerung), da rememoração (Andenken) e do esquecimento (Vergessen/ Vergessenheit) e por sua contraparte (eingedenk sein), o não esquecimento ativo.

A obra benjaminiana se coloca permanentemente tarefas que implicam passagens ou ultrapassagem de fronteiras (das fronteiras da filosofia tradicional, do fenômeno para a idéia, do original para a tradução, com a incorporação dos primeiros termos, sua subsunção aos segundos termos, que a eles se seguem). $\mathrm{O}$ pensamento de Benjamin situa-se ele mesmo num lugar de fronteira, que busca efetuar a transição entre sensível e cognoscível, o âmbito fenomenal e o ideativo, o teológico e o profano, origem e meta (ou original e tradução). Pensador e escritor que vivenciou e refletiu como nenhum outro em sua época sobre a condição de estar entre du-

\footnotetext{
${ }^{1} \mathrm{O}$ presente texto foi também apresentado, em versão ligeiramente diversa, no Colóquio Walter Benjamin: Formas de Percep̧̧ão Estética na Modernidade, realizado em abril de 2007, no Instituto Goethe de Salvador, e deverá sair, na versão anterior, em publicação com as atas desse evento.
}

* (WEIGEL, S. "Die Lektüre, die na die Stelle der Übersetzung tritt. Benjamins psychoanalytische Reformulierung seiner Theorie de Sprachmagie" Em NIBBRIG, C.H. (org.) Übersetzen:Walter Benjamin. Frankfurt am Main: Suhrkamp, 2001 : 241-3.) 
- (STAROBINSKI, J. "Melancholie und Spiegelbild. Eine Lektüre von Baudelaires 'Le cygne'" In Merkur. Deutsche Zeitschrift für europäisches Denken. V. 42 (9/10), 1988: 751.)

(BOLLE, W. Fisiognomia da metrópole moderna. São Paulo: Edusp, 1994: 31920) as línguas e duas culturas (a alemã e a francesa e, adicionalmente, entre a tradição cultural alemã e a judaica), e que o destino levou a um lugar de fronteira: Port Bou, entre a França e a Espanha para cumprir outra tarefa: a de terminar com a própria vida e com isso, com a própria atividade do pensamento, de modo voluntário ainda que profundamente condicionado pela premência da situação em que vivia. O horizonte permanente da morte, sob o qual Benjamin inscreveu sua escrita de modo consciente, é também ele mesmo circunscrito pela liminaridade que caracterizou tantos outros lugares de sua reflexão. Em nossa condição de leitores de sua obra, resta-nos levar a sério essa tarefa de leitura enquanto rememoração e também de pranteamento - não de um autor - mas de um texto, objeto ao mesmo tempo morto (pois acabado) e vivo (pois aberto a infindáveis interpretações).

Convém talvez aqui relembrar que a palavra alemã para luto, pranteamento, Trauer possui diferentes sentidos: ${ }^{2}$ luto, pranto ou tristeza; etimologicamente, a palavra é aparentada ao verbo truren, que também significa baixar os olhos, indicando uma referência ao tradicional gesto do lutuoso ou melancólico de abaixar a cabeça. Jean Starobinski, em seu estudo sobre a melancolia no poema "Le cygne" de Baudelaire, liga a etimologia do verbo pensar a dos verbos pender e pesar. A figura típica do lutuoso melancólico é a de um ser pensativo, imerso na contemplação, cuja cabeça pesa, pende para baixo. Essa ligação pode ser reencontrada na rede conceitual urdida pelas reflexões benjaminianas, ligada ao núcleo etimológico constituído pelo verbo pensar em alemão, denken. A ele se ligam termos fundamentais da "cartografia da memória"* traçada por Benjamin em seus textos: as palavras Gedächtnis, Andenken e Eingedenken carregam todas a marca dessa etimologia que inclui, igualmente, o significado de pesar, tanto nas acepçôes concretas, quanto nas figuradas (pesar como verbo: ter peso, ou ponderar, considerar; pesar, como substantivo, significando tristeza), A elas se agrega um sentido adicional: o do rememorar, relembrar, o que vincula essa constelação de conceitos ao âmbito de uma re-elaboração do passado pelo trabalho da memória.

Também o tradutor, leitor privilegiado de uma obra, deve remontar ao texto original através de um percurso de leitura que é

${ }^{2}$ Cf. KLUGE, F. Etymologisches Wörterbuch der deutschen Sprache, verbete trauern e verbete denken. Retomo nos próximos parágrafos uma reflexão que já desenvolvi em outra sede. Cf. LAGES, S.K. Walter Benjamin. Tradução e melancolia. São Paulo: Edusp, 2002: 153-4. 
eminentemente rememorativo: todo esforço de reescrita textual é de natureza (re)memorativa, opera um desdobramento tanto no plano reflexivo quanto no plano sensível e/ou material de um texto. E por constituir o produto de uma rememoração do texto original, o texto traduzido cria um outro texto que não é cópia, reprodução, mas sim "testemunho do seu original - testemunho diferido, como sempre acontece com as imagens da memória”, como assinala o crítico e tradutor português de Walter Benjamin João Barrento, num bonito texto sobre a tradução dos clássicos. ${ }^{*}$ Por outro lado, para existir, toda tradução deve necessariamente realizar uma diabólica operação de esquecimento do texto original, como realçou Haroldo de Campos, leitor de Benjamin, ao finalizar suas reflexões sobre sua própria tradução de trechos do Fausto de Goethe, designando sua tarefa de tradutor como "desmemória parricida" que "não é piedosa, nem memorial":

Flamejada pelo rastro coruscante de seu Anjo instigador, a tradução criativa, possuída de demonismo, não é piedosa nem memorial: ela intenta, no limite, a rasura da origem: a obliteração do original. A essa desmemória parricida chamarei "transluciferação". *

Como operação fundamentalmente dupla, de uma duplicidade aporética e não superável, o texto traduzido encontra-se num entre-lugar, entre o passado do texto original e o futuro de um texto a ser traduzido, tarefa essa que se coloca no tempo presente. Para Benjamin, como de resto para todo tradutor, há, como afirma Peter Szondi, um eco do passado [Nachklang der Vergangenheit] no presente e um presságio do futuro no passado [Vorklang einer Zukunft]. Se, para Benjamin, a memória é a responsável pela conservação do narrado e por assegurar sua transmissão futura, é preciso levar em consideração o que lhe permite existir: a experiência da percepção e do apagamento, ou melhor, da neutralização das percepções por meio da vivência de choques tornados elementos da experiência, por um lado, e a experiência do esquecimento, isto é, a impossibilidade de reativar conscientemente imagens do passado, por outro.*

Benjamin recorre a Freud, a Bergson e a Proust para explicar o complexo mecanismo da memória e sua articulação à temporalidade, e sua relevância na poética de Baudelaire. É no embate entre a defesa contra os estímulos e a percepção de que tais estímulos o afetam que a consciência do poeta (e sua precária identidade) se constrói. Essa construção só pode ser levada a cabo de maneira
" (BARRENTO, J. "Babel já não mora aqui?" A escala do meu mundo. Lisboa: Assírio \& Alvim, 2006: 56.)

(CAMPOS, H. de. Deus e o diabo no Fausto de Goethe. São Paulo: Perspectiva, 1981: 209.)

"(SZONDI, P. “Hoffnung im Vergangenem. Über Walter Benjamin." Schriften. Frankfurt am Main: Suhrkamp, 1978: 285.)

" (BENJAMIN, W. "O narrador. Considerações sobre a obra de Nicolai Leskov". Obras escolhidas I. Magia e técnica, arte e política. Tradução de Sérgio Paulo Rouanet. São Paulo: Brasiliense, 1985: 210.) 
(BENJAMIN, W. "Sobre alguns temas em Baudelaire". Tradução de Hermerson Alves Baptista Obras escolhidas III. Charles Baudelaire. Um lírico no auge do capitalismo. São Paulo: Brasiliense, 1989: 111.)

(BAUDELAIRE, C. O Spleen de Paris. Pequenos poemas em prosa. Tradução e apresentação de Leda Tenório da Motta. Rio de Janeiro: Imago, 1995: 19-20)

dupla. Em Baudelaire, essa duplicidade se manifesta de múltiplas formas. Benjamin destacou algumas delas: "Baudelaire fixou esta constatação na imagem crua de um duelo, em que o artista, antes de ser vencido, lança um grito de susto. Esse duelo é o próprio processo de criação. Assim, Baudelaire inseriu a experiência do choque no âmago de seu trabalho artístico." ${ }^{\prime *}$ texto comentado por Benjamin é um dos "pequenos poemas em prosa" de O Spleen de Paris, de Baudelaire, e chama-se "O confiteor do artista". Nele, o artista se assusta subitamente diante da visão de uma natureza idílica, cuja beleza não-mediada, por assim dizer, espontânea e tendencialmente eterna, rivaliza com a do objeto estético a ser projetado pelo poeta, que de antemão prevê sua derrota futura, em termos da realização desse projeto. Não por acaso, nesse texto de inspiração ironicamente anticartesiana, ${ }^{3}$ encontra-se próxima (mas não exatamente) ao centro do texto uma longa série de exclamações, em que a descarga dos afetos se concretiza como dissolução ou dispersão da identidade do eu lírico:

Que grande delícia afogar o olhar na imensidão do céu e do mar! Solidão, silêncio, incomparável castidade do azul! um pequeno veleiro tremulante no horizonte, que imita em sua pequenez e isolamento minha existência irremediável, melodia monótona das vagas, todas essas coisas pensam por mim, ou penso eu por elas (pois na grandeza do devaneio o 'eu' logo se perde!); pensam, dizia, mas musicalmente e pitorescamente, sem argúcias, sem silogismos, sem deduções.

Baudelaire repete aqui, de forma ainda mais enfática e irônica, o "je pense" cartesiano, tantas vezes repetido no poema "Le cygne": A subjetividade moderna se define, pois, por um lado, por uma relação diversa com as coisas, pela qual o sujeito ou se torna objeto, ou se dissolve em sua própria subjetividade, e as coisas se humanizam, tornando-se capazes inclusive de "pensar"; por outro lado, é ela que identifica nas coisas traços de um tipo de pensamento musical e pitoresco, "sem argúcias, sem silogismos, sem deduções", e que aparece como desejável. Na interpretação de Benjamin, essa reversão das relações sujeito-objeto não pode ser entendida senão pelo recurso às tremendas modificações introduzidas pelo capitalismo industrial na vida social e na paisagem urbana da Paris do sé-

\footnotetext{
${ }^{3} \mathrm{O}$ anticartesianismo de Baudelaire já foi apontado por Ross Chambers, em seu ensaio sobre o poema "Le cygne", "Mémoire et mélancholie". Cf. CHAMBERS, R. "Mémoire et mélancolie". Mélancolie et opposition. Les débuts du modernisme en France. Paris: José Corti, 1987: 183.
} 
culo XIX. Mas esse recurso não se deixa reduzir a relações de causa e efeito, nem admite explicações de tipo psicológico-causal, como assinalou Max Pensky, ${ }^{*}$ já que as fontes da poética baudelariana se encontram precisamente nos diferentes modos de relação que se estabelecem entre a visão poética e seus objetos.

Esse complexo jogo de inter-relações entre produção poética e vida social é, pois, uma das formas pelas quais a duplicidade baudelairiana, em sua melancolia, reiteradamente se manifesta para marcar a necessidade de assimilar a visão poética do passado e simultaneamente destruí-la, aliás, para assimilá-la justamente sob o signo de sua negação ou destruição. Nesse sentido, é igualmente pertinente a observação de Winfried Menninghaus, ${ }^{4}$ que sublinha uma observação de Benjamin (que centrou sua análise da lírica baudelairiana na figura da métropole), segundo a qual descrições de Paris praticamente não comparecem nos poemas de As flores do $\mathrm{Mal}$, mas nem por isso a figura da metrópole, também enquanto uma figura interna, deixa de ser literariamente relevante.

Num bonito ensaio, Beryl Schlossmann* fixa na palavra Kreuzungen [cruzamentos] as tensões e ambigüidades, que atravessam as relaçôes entre Baudelaire, o labiríntico espaço urbano, e Walter Benjamin e a sua teoria da tradução, assim como apresentada no texto "A tarefa do tradutor". Esse ensaio serve de prólogo às suas próprias traduçôes de Baudelaire, cujo caráter eminentemente experimental é patente (alguns comentadores utilizaram pejorativamente a palavra künstlich, artificial; prefiro atribuir às traduçôes de Benjamin o adjetivo "experimental", seguindo uma reflexão feita por Alexander Honold ao tratar do conceito de leitura e de crítica no pensamento benjaminiano). ${ }^{*}$ Por meio desse gesto claramente experimental, as traduçōes benjaminianas procuram superar a situação de epigonalidade em relação ao Tradutor e à Tradução que até hoje marcam a recepção da obra de Baudelaire na Alemanha: a do poeta simbolista-decadentista alemão Stefan George. Essa tradução de Baudelaire - considerada um marco na história da recepção de Baudelaire na Alemanha - foi publicada em 1901 (duas décadas antes do experimento tradutório benjaminiano).

\footnotetext{
4 "Descrições de Paris são praticamente irrelevantes em As flores do Mal: Baudelaire não descreve nem os habitantes nem a cidade. No entanto, a metrópole - e é esse o cerne da interpretação de Benjamin - é uma 'potência marcante' de primeira ordem: sua estrutura enquanto experiência encontra-se incluída como uma figura oculta em uma série de obras suas." Cf. MENNINGHAUS, W. Walter Benjamins Theorie der Sprachmagie. Frankfurt am Main: Suhrkamp, 1980: 143.
}

(PENSKY, M. Melancholy dialectics. Walter Benjamin and the play of mourning. Amrherst: The University of Massachussets Press, 1993: 157.)

" (SCHLOSSMANN, B. "Pariser Treiben". Em NIBBRIG, C. H. Übersetzen: Walter Benjamin. Op. cit.: 280310.)

(HONOLD, A. "Kritik und Magie. Elemente einer Theorie des Lesens nach Benjamin". Der Leser Walter Benjamin. Bruchstücke einer deutschen Literaturgeschichte. Berlim: Vorwerk 8, 2000: 30.) 
(SCHLOSSMANN, B. Op. cit.: 284-7.)

- (BENJAMIN, W. "A tarefa do tradutor". Tradução de Susana Kampff Lages. Em HEIDERMANN, W. Clássicos da teoria da tradução. Antologia bilíngüe: alemãoportuguês. Florianópolis: NUT/ UFSC, 2001: 211-2.)
De fato, muitos são os elementos que se entrecruzam na relação entre Baudelaire, Benjamin e a tradução, tema que já tem atraído a atenção de alguns estudiosos. A começar pelo fato de Baudelaire ter sido ele mesmo tradutor - e de obras nada secundárias para sua própria poética e para a interpretação que dela faz Walter Benjamin. Cabe aqui lembrar, com Beryl Schlossmann, de dois autores traduzidos por Baudelaire e duas de suas respectivas obras: Edgar Alan Poe ( $O$ homem da multidão) e Thomas de Quincey (Confissóes de um comedor de ópio). O processo de traduzir essas obras foi fundamental na configuração da própria poética de Baudelaire. Como sublinha Schlossmann, também enquanto tradutor Baudelaire abre caminhos à modernidade (e talvez se deva dizer: à pós-modernidade): sua tradução de De Quincey afirmase no mesmo plano do original, anulando-se enquanto tradução e afirmando-se como recriação. Essa inversão categorial entre original e tradução - que afinal de contas Benjamin não chega a defender em seu famoso ensaio sobre "A tarefa do tradutor" - é levada a cabo por Baudelaire não apenas nessa tradução especificamente mas também em outros escritos sobre literatura e arte como mostra em seu ensaio Schlossmann.

De fato, com suas traduções, Benjamin não pretendia efetuar uma reversão categorial entre o texto original e sua tradução, diferentemente de Stefan George, o qual explicitamente o pretendia, tanto é que denominou suas traduções de Umdichtungen (recriações ou "transcriaçōes", se utilizarmos a terminologia do poeta brasileiro Haroldo de Campos, que foi também leitor privilegiado do ensaio benjaminiano sobre a tarefa do tradutor e tradutor ele mesmo de poemas de George) ou Verdeutschungen ("germanizaçōes", em alemão, um sinônimo para tradução para a língua vernácula). No ensaio sobre a tarefa do tradutor, Benjamin* se contrapõe à visão da tradução como vernacularização, como domesticação da língua estrangeira, visão essa que está, sem dúvida, na base da tradução de George. Em sua defesa de uma tradução "estrangeirizante", Benjamin remete às idéias de Rudof Pannwitz, um filólogo que fazia parte do círculo de George, para enfatizar a importância de amoldar a língua do texto original à língua do tradutor, fazendo com que a língua do tradutor seja violentamente abalada pela língua do texto original. Com suas recriações, George queria erigir um "monumento alemão" (ein deutsches denkmal), o que de fato conseguiu, dado o sucesso recepcional de sua empreitada, que se afirma até hoje como 
a versão mais lida e citada de As Flores do Mal em língua alemã. A tradução benjaminiana da seção "Quadros Parisienses" de As Flores do Mal e as demais traduções de outras seções do livro permanecem, do ponto de vista de sua recepção, sendo uma entre várias outras empresas tradutórias, como documenta o exaustivo estudo de Thomas Keck. ${ }^{*}$ Se suas traduções não lograram obter notoriedade, já não se pode dizer o mesmo do breve ensaio de apresentação a essas traduçõos: o texto denominado "A tarefa do tradutor", que se tornou a quintessência não só do pensamento benjaminiano sobre tradução, mas converteu-se também, depois das leituras realizadas por Jacques Derrida, Paul de Man, Homi Bhaba, entre outros, um texto de citação obrigatória em diferentes áreas das Ciências Humanas, notadamente, nos estudos de literatura, cultura e tradução de extração desconstrutivista, o que muitas vezes lhe tem feito correr o risco da banalização.

Tanto na fortuna crítica benjaminiana, quanto nos estudos da tradução em geral, por muito tempo ignorou-se que esse texto era não tanto uma reflexão teórica abstrata fechada e ligada apenas a um outro texto que lhe era anterior ("Sobre a linguagem em geral e sobre a linguagem do homem”), mas que era um prólogo, um texto de uma apresentação. Em princípio o texto de um prefácio deveria cumprir a função de, por um lado, dar uma interpretação da poética do autor traduzido e, por outro, explicar a visão ou os procedimentos do tradutor. No entanto, o fato de ser esse texto uma apresentação - na verdade um tanto enigmática - de um conjunto de traduções de poemas de Baudelaire, autor que sequer é citado no texto, é um dado intrigante que afinal passou, há algum tempo, a ser objeto de investigação, sobretudo, dos estudiosos da obra de Benjamin. Destaco em particular dois ótimos ensaios: o já citado de Beryl Schlossmann e o texto "'Como a luz do abismo alegra o que nele cai.' A tradução de Baudelaire por Benjamin", de Heiner Weidmann. Por outro lado, também estudiosos da obra de Baudelaire têm dedicado sua reflexão aos poemas traduzidos por Benjamin - este é o caso de estudos monográficos acadêmicos, como por exemplo, o estudo eminentemente documental de Thomas Keck, Der deutsche Baudelaire, de 1990/1, em dois volumes, acima citado, e o estudo mais recente, de 2005, com caráter mais interpretativo, de autoria de Mark Behrens, ${ }^{5}$ tratando especificamente das traduções de Baudelaire feitas no início do

\footnotetext{
${ }^{5}$ Agradeço a João Barrento a indicação desse trabalho.
}

(KECK, T. Der deutsche Baudelaire. Studien zur übersetzerischen Rezeption der Fleurs du mal. Heidelberg: Carl Winter, 1991.)

" (WEIDMANN, H. "Wie Abgrunds Licht den Stürzenden beglücket'. Zur Benjamins Baudelaire Übersetzung". Em NIBBRIG, C.H.. Op. Cit.: 311-24.) 
- (BEHRENS, M. Charles Baudelaire bei Max und Margarete Bruns. Übersetzung und Eigenproduktion in J. C. C. Bruns' Buchverlag (1881-1929). Tese de doutoramento, Fakultät für Linguistik und Literaturwissenschaft der Universität Bielefeld, 2005.)

- (Idem: 21.)

(BENJAMIN, W. "Übertragungen aus anderen Teilen der 'Fleurs du mal'". Gesammelte Schriften. Frankfurt am Main: Suhrkamp, 1991: 65)

- ("Charles Baudelaire. Tableaux parisiens. Deutsche Übertragung mit einem Vorwort über die Augabe des Übersetzers". Gesammelte Schriften. Frankfurt am Main: Suhrkamp, 1991: Vol. IV/1, 7-63.)

(BEHRENS, M. Op. cit.: 8.)

- (GOETHE, J.W. apud NICOlETTI, A. "Einleitung". Übersetzung als Auslegungin Goethes Wet-östlichem Diwan. Tübingen \& Basel: A. Francke 2002: 9. Tradução minha.) século passado, pelo casal de editores Max e Margarete Bruns. ${ }^{*}$ As traduções do casal Bruns de As flores do mal vêm a ser publicadas somente no ano de 1923, ou seja, são praticamente contemporâneas das versões benjaminianas. Apontando para a situação analogamente epigonal do casal Bruns (sua edição sai quando a de Stefan George já está na sexta edição), Behrens* destaca um detalhe relevante: o casal de editores denomina suas traduções de " $\mathrm{Na}$ chdichtungen" - numa tradução literal, seria algo como "pós-criaçôes" -, uma palavra em que o caráter posterior e reprodutor da tradução em relação ao original é sublinhado e que também parece fazer eco à palavra utilizada por Stefan George para denominar as próprias traduções [Umdichtungen]. Walter Benjamin," por sua vez, irá usar uma palavra mais neutra e convencional (Übetragung) para dar título a suas traduções de poemas de Baudelaire, acompanhadas do famoso prefácio sobre a tarefa do tradutor: "Charles Baudelaire. Tableaux parisiens. Tradução alemã com um prefácio sobre a tarefa do tradutor", " não denotando nenhuma pretensão maior com essa denominação.

Como enfatiza Behrens, ${ }^{*}$ Walter Benjamin, nas reflexões finais de seu ensaio sobre a "A tarefa do tradutor", privilegia um tipo de tradução que já fora proposto como o mais adequado por Goethe em um texto famoso, constante do volume de poemas do final da vida, o Divã Ocidental-Oriental: a tradução interlinear:

Uma tradução que pretenda se identificar com o original aproximase afinal da versão interlinear e facilita altamente a compreensão do original; por meio dela somos levados, aliás, impelidos ao texto-base e assim por fim se fecha todo o círculo, no qual se move a aproximação entre o estrangeiro e o nativo, o conhecido e o desconhecido.

Entretanto, ao defender esse - do ponto de vista empírico, temerário - modo de traduzir, já anteriormente defendido por Goethe, Benjamin não recorre à citação direta desse clássico texto goetheano, preferindo, como indicamos mais acima, citar textualmente um filólogo do círculo de Stefan George, Rudolf Pannwitz, citação essa que, junto com outro texto de Mallarmé, constitui as únicas citações textuais no famoso ensaio. Essa forma estrangeirizante de traduzir preconizada por Goethe e por Pannwitz - e na esteira deles, por Benjamin - procura seguir literalmente as palavras do original, ainda que forçando a sintaxe da própria língua, para deixar que ela seja violentamente abalada pela língua estrangeira. Nesse ponto, Benjamin na verdade distancia-se de Stefan George, que, 
como demonstra Behrens, ${ }^{*}$ no caso específico das traduções de $A s$ Flores do Mal, segue o caminho oposto, procurando eliminar todo e qualquer rastro da língua estrangeira em suas versóes, sendo as suas traduçôes, desse ponto de vista, verdadeiras "germanizaçôes" (por exemplo, ele escolhe a palavra Duft ao invés da palavra Parfüm, igualmente existente e corrente na língua alemã, para traduzir a palavra francesa parfum; escolhe a palavra alemã Trübsinn para traduzir o estrangeirismo spleen). Outro elemento de divergência é o fato de George eliminar as imagens por demais cruamente sensoriais e repulsivas, tendo em vista privilegiar uma tradução sublimadora, idealizadora ou espiritualizadora de Baudelaire (onde o subtítulo das Flores do Mal, denominado "Spleen et Ideal" se transforma em alemão em Trübsinn und Vergeistigung), na qual a teoria das correspondências tem mais peso que a idéia da alegoria.

No entanto, em que pese a valorização por parte de Benjamin do elemento alegórico em Baudelaire, é possível detectar que, em sua prática como tradutor, ele também contradiz o procedimento que considera mais adequado - um fato aliás que pode ser observado na prática de muitos tradutores que refletem sobre sua própria prática e sobre o fenômeno da tradução em geral. Qualquer tradutor sabe que não é possível se utilizar rigidamente de um único procedimento de tradução ao longo de toda uma obra, ainda que se possam privilegiar, em princípio, determinados procedimentos em detrimento de outros. Mark Behrens ${ }^{*}$ nos traz em seu estudo um divertido exemplo de Benjamin como tradutor à maneira das belles infidèles do século XVIII, em rota de colisão com suas próprias reflexões sobre a tarefa do tradutor. No poema "Danse macabre", em que um esqueleto feminino faz o convite à dança mortal, a primeira estrofe é traduzida por Benjamin de modo bastante distanciado da dicção original, uma verdadeira tradução "livre":

Fière, autant qu'un vivant, de sa noble stature, Avec son gros bouquet, son mouchoir et ses gants, Elle a la nonchalance et la désinvolture

D'une coquette maigre aux airs extravagants

(Charles Baudelaire)

Kein Lebender pocht mehr auf seine Größe”

Als sie die Strauss und Handschuh an sich presst

Und in der Haltung die verwegne Blöße

Der hagern Kurtisane sehen lässt.

(Trad. Walter Benjamin)
' (BEHRENS, M. Op. cit.: 137-42.)

"(Idem: 158-64.) 
Emproada como viva, orgulhosa a estatura, Com seu grande buquê, mais as luvas e o lenço, Possui a languidez como a desenvoltura

De uma coquete magra e de ar de sonho imenso.

(Trad. Ivan Junqueira)

Vivente algum se ufana mais de sua estatura

Do que a que preme buquê e luvas contra si

E deixa transparecer na postura

A nudez atrevida da magra cortesã

(Trad. Susana K. Lages, a partir de Walter Benjamin) 


\section{Susana Kampff Lages}

Susana Kampff Lages é professora da Universidade Federal Fluminense. Publicou Walter Benjamin: tradução e melancolia (Edusp, Prêmio Jabuti 2003) e João Guimarães Rosa e a saudade (Ateliê Editorial, 2003). Traduziu para a Editora 34 o romance $O$ desaparecido: Amerika, de Franz Kafka. Sua pesquisa abrange os campos da teoria literária, dos estudos de tradução e da literatura comparada, com especial foco em autores de língua portuguesa e alemã.

\section{Resumo}

O trabalho realiza uma reflexão sobre as relações entre a obra de Walter Benjamin e Charles Baudelaire a partir de uma interpretação da própria teoria e prática da tradução poética benjaminiana. Parte-se aqui do pressuposto de que a literatura é um imenso acervo de relaçóes intertextuais, eminentemente rememorativas, no interior do qual a tradução tem um papel de destaque. A particular relação do leitor, crítico e poeta Walter Benjamin com o poeta Charles Baudelaire é paradigmática desse movimento rememorativo na modernidade literária.

\section{Abstract}

The present paper reflects on the connections between Walter Benjamin and Charles Baudelaire, taking as a starting point an interpretation of Benjamin's own translation theory and practice. We assume literature as an immense mass of mainly memorative intertextual relations, inside which the work of translation has a relevant role. The particular relationship of Walter Benjamin as reader, critic and himself a poet with Charles Baudelaire is paradigmatic of this memorative movement in modern literature.

\section{Résumé}

L'essai propose une réflexion sur les rapports entre l'œuvre de Walter Benjamin et celle de Charles Baudelaire, prenant pour point de départ une interprétation de la pratique et de la théorie de la traduction poétique benjaminienne. Nous partons de l'idée que la littérature est un fonds immense de rapports intertextuels, éminemment remémoratifs, à l'intérieur duquel la traduction joue un rôle important. Le rapport particulier du lecteur, critique et poète Walter Benjamin au poète Charles Baudelaire est paradigmatique de ce mouvement de remémoration dans la modernité littéraire.
Palavras-chave: Baudelaire; Benjamin; tradução.

Key words: Baudelaire; Benjamin; translation.

Mots-clés: Baudelaire; Benjamin; traduction.

Recebido em 21/05/2007

Aprovado em 30/06/2007 